\title{
Ricardian Comparative Advantage with Intermediate Inputs
}

\author{
Alan V. Deardorff
}

The University of Michigan

Revised, August 30, 2004 


\title{
ABSTRACT \\ Ricardian Comparative Advantage with Intermediate Inputs
}

\author{
Alan V. Deardorff \\ The University of Michigan
}

This paper examines the role of comparative advantage in a Ricardian trade model with intermediate inputs. The main issue is how to define comparative advantage when there are intermediate inputs. Several definitions are suggested, differing in whether they are based on the total costs of producing goods, on the one hand, or on the labor requirements per dollar of value added, on the other; and differing also - since both approaches require prices of intermediate inputs - in the choice of prices for making these comparisons. Standard "predictions" of trade patterns in terms of comparative advantage are easily derived, but using the value-added definition and actual prices that prevail with trade. These have the usual implications for patterns of specialization based on rankings, or "chains," of comparative advantage. However, because these prices are not given and may depend on barriers to trade, these comparisons are less informative than in Ricardian models with only final goods. In fact, trade patterns here can be so sensitive to trade costs that any such comparison predicting the trade in particular goods fails to be robust. In spite of this, the gains from trade are unambiguous in these Ricardian models, with imported inputs actually providing an additional source of gain from trade. Also, a weaker statement of the Law of Comparative Advantage, using only a correlation or average relationship between relative autarky prices and trade, is also valid under weaker assumptions than in more general models.

Keywords: Comparative advantage

Ricardian model

Intermediate inputs

JEL Subject Code:

F11 Neoclassical Trade Models

\section{Correspondence:}

Alan V. Deardorff
Department of Economics
University of Michigan
Ann Arbor, MI 48109-1220

Tel. 734-764-6817

Fax. 734-763-9181

E-mail: alandear@umich.edu

http://www-personal.umich.edu/ alandear/ 
August 30, 2004

\title{
Ricardian Comparative Advantage with Intermediate Inputs"
}

\author{
Alan V. Deardorff \\ The University of Michigan
}

Here I try to spell out how comparative advantage may be defined, and how it operates, in a Ricardian model with intermediate inputs. There has been increasing interest in recent years, both theoretically and empirically, in the splitting of production processes across international locations through outsourcing, foreign direct investment, and other means. ${ }^{1}$ Thus the role of intermediate inputs in international trade seems to be viewed as increasingly important. A prerequisite to understanding that role may be to capture it within our simplest, Ricardian, trade model. ${ }^{2}$

The role of intermediate inputs in that model, as we will see and as is already well known, is relatively straightforward if countries differ only in their labor requirements for production of final and intermediate inputs, but do not differ in the input-output coefficients that relate inputs to outputs. In this case Jones (1961) showed quite generally

\footnotetext{
* In writing this paper, I have benefited from conversations with, and comments of, Harry Flam, Juan Carlos Hallak, Henrik Horn, Ed Leamer, and Robert Stern, plus two anonymous referees. This paper was begun while I was visiting at the Institute for International Economic Studies, Stockholm University, during the fall of 2002, during which I benefited from financial support from Tore Browaldh's Research Foundation.

${ }^{1}$ See Deardorff (2001) for my own take on this issue, including in a Ricardian model. See also Jones (2000) and Grossman and Helpman (2002) on the theory, and Hummels et al. (2001) on empirics. Feenstra and Hanson (2003) provide a survey.

${ }^{2}$ See Appendix A for review of how previous authors have, and have not, dealt with this topic.
} 
that standard applications of comparative advantage apply. ${ }^{3}$ But without this assumption, he and others have found the role of comparative advantage with intermediate inputs difficult to pin down. That is no less true here, but at least we can map out, perhaps more completely than before, what can and cannot be said, both when input-output coefficients differ and when they do not. Even when they are the same, trade patterns can be so sensitive to trade costs that comparative advantage is less useful than might be supposed for delineating trade patterns.

\section{Defining Comparative Advantage with Intermediate Inputs}

The definition of comparative advantage in a Ricardian Model without intermediate inputs is straightforward, even if it is often difficult for our students to understand. A country has a comparative advantage in producing a good, relative to some other good and compared to some other country, if its relative labor cost is low. Letting $a_{g}^{c}$ be the amount of labor needed to produce one unit of good $g$ in country $c$, country $c_{1}$ has a comparative advantage in good $g_{1}$ relative to some other good $g_{2}$, compared to another country $c_{2}$, if its labor cost of producing good $g_{1}$ relative to $g_{2}$ is lower than that same relative cost in the other country:

$$
\frac{a_{g_{1}}^{c_{1}}}{a_{g_{2}}^{c_{1}}}<\frac{a_{g_{1}}^{c_{2}}}{a_{g_{2}}^{c_{2}}}
$$

By this definition, if these are the only two goods and countries in a world of perfect competition, and if trade is either free or restricted (but not perversely subsidized), then we have the following familiar implications:

\footnotetext{
${ }^{3}$ This is the assumption made, for example, by Dixit and Grossman (1982) and Sanyal (1983) in applying comparative advantage to sort vertical stages of production between countries. Both assumed, quite
} 
- Trade will necessarily entail $c_{1}$ exporting $g_{1}$ and $c_{2}$ exporting $g_{2}$.

- For trade to be beneficial to the two countries, this must be the pattern of their trade.

- The size of this total benefit will be larger the more resources (in this case labor) each country is able to reallocate into the industry in which it has comparative advantage.

If the numbers of either goods or countries are larger than two, then the same definition can be used, as I will verify later here, but the implications of comparative advantage are slightly weaker. With more than two goods, the two goods for which (1) holds may both be exported by the same country (in exchange for other goods). And with more than two countries, the two countries for which (1) holds may both export or import the same good (to or from other countries). Nonetheless, if two countries do exchange two goods with each other under these assumptions, then each country must export the good in which it has comparative advantage by the definition above.

In trade theory we are accustomed to this simple story becoming murkier if costs are variable rather than constant. For then the costs that we compare in (1) will be different depending on the context. Whatever the relative costs may have been in autarky, for example, we may find the cost of the exported good rising and that of the imported good falling as a result of trade, reducing and perhaps eliminating the relative cost advantage identified in (1). Indeed, in the Heckscher-Ohlin Model with free trade and factor price equalization, all costs are the same in the trading equilibrium, and no comparative cost advantage can be observed. If trade is less than free, so that differences

naturally, that one unit of input is needed for one unit of output at every stage. 
in production costs are necessary in order to overcome tariffs or transport costs, then an inequality like (1) will hold for the costs observed in the trading equilibrium, but as a predictor of trade it is both trivial and after the fact.

For these reasons, it is customary to use autarky costs to define comparative advantage in variable-cost models. Autarky costs - because they depend on a country's underlying technology, factor endowments, and tastes but not at all on trade policies and impediments that may influence the trading equilibrium - provide a primitive theoretical predictor of the pattern of trade. The drawback is that autarky costs may be difficult or impossible to observe empirically. But this is not a concern in a theoretical analysis, and even in empirical work the problem can be finessed by imposing additional structure so as to infer autarky costs from other primitives, such as factor endowments.

The advantage of a Ricardian Model, one might think, is that we need not worry about costs being variable. But in fact, once we allow intermediate inputs, the same problem emerges. The cost of producing a good depends not just on the labor needed for the final stage of its production, but also on the costs of intermediate inputs, and these may change with trade and with trade policy, if these inputs are traded.

Consider the cost in country $c$ of producing a good $g$, one unit of which requires input of $b_{h g}^{c}$ units of each good $h$, perhaps including good $h=g$ itself. With $a_{g}^{c}$ now being the amount of $c$ 's labor needed for just the final stage of $g$ 's production, and with $p_{h}^{c}$ the price in units of $c$ 's labor of each good $h$ in country $c$, the total cost (in labor units) of good $g$ in country $c$ is

$$
\lambda_{g}^{c}=a_{g}^{c}+\sum_{h} p_{h}^{c} b_{h g}^{c}
$$


A seemingly straightforward extension of (1) to the case of intermediate goods, then, simply replaces the direct costs in (1) with these total costs:

$$
\frac{\lambda_{g_{1}}^{c_{1}}}{\lambda_{g_{2}}^{c_{1}}}=\frac{a_{g_{1}}^{c_{1}}+\sum_{h} p_{h}^{c_{1}} b_{h g_{1}}^{c_{1}}}{a_{g_{2}}^{c_{1}}+\sum_{h} p_{h}^{c_{1}} b_{h g_{2}}^{c_{1}}}<\frac{a_{g_{1}}^{c_{2}}+\sum_{h} p_{h}^{c_{2}} b_{h g_{1}}^{c_{2}}}{a_{g_{2}}^{c_{2}}+\sum_{h} p_{h}^{c_{2}} b_{h g_{2}}^{c_{c_{2}}}}=\frac{\lambda_{g_{1}}^{c_{2}}}{\lambda_{g_{2}}^{c_{2}}}
$$

However, although the $a$ 's and $b$ 's are technological parameters specific to the two countries being compared, the prices are not parameters at all. They are equilibrium values determined in markets, and in general they depend on the behavior and policies of these and perhaps other countries. At a minimum, this gives us different definitions of comparative advantage depending on which prices are used in (3). And there is no guarantee that any of these definitions will even plausibly explain trade.

In the remainder of this section I will specify several different definitions and comment briefly on their more obvious properties. Then in subsequent sections, as I explore what can and cannot be said in the Ricardian Model, I will relate the results to these definitions in order to see which of them, if any, provide useful implementations of the concept of comparative advantage in terms of being able to delineate the patterns of trade and the gains from trade. At the end of the paper I will attempt to conclude which of these definitions is most useful.

Comparative Advantage Definition 1 (Direct costs per unit): Country $c_{1}$ has a comparative advantage in good $g_{1}$, compared to country $c_{2}$ and good $g_{2}$, if equation (1) holds.

\section{Comparative Advantage Definition 2 (Total costs per unit at autarky prices):}

Country $c_{1}$ has a comparative advantage in good $g_{1}$, compared to country $c_{2}$ and 
good $g_{2}$, if equation (3) holds with prices $p_{h}^{c_{i}}$ being the autarky prices in the respective countries $c_{i}=c_{1}, c_{2}$.

\section{Comparative Advantage Definition 3 (Total costs per unit at actual prices):}

Country $c_{1}$ has a comparative advantage in good $g_{1}$, compared to country $c_{2}$ and good $g_{2}$, if equation (3) holds with prices $p_{h}^{c_{i}}$ being the actual prices that prevail in the respective countries in the actual trading equilibrium, including actual barriers to trade that are both natural (e.g., transport costs) and artificial (e.g., tariffs).

Comparative Advantage Definition 4 (Total costs per unit at undistorted - i.e., free-trade-prices): Country $c_{1}$ has a comparative advantage in good $g_{1}$, compared to country $c_{2}$ and good $g_{2}$, if equation (3) holds with prices $p_{h}^{c_{i}}$ being the prices that would prevail in the respective countries in a free-trade equilibrium, with actual natural barriers to trade but no artificial ones.

\section{Comparative Advantage Definition 5 (Total costs per unit at frictionless free} trade prices): Country $c_{1}$ has a comparative advantage in good $g_{1}$, compared to country $c_{2}$ and good $g_{2}$, if equation (3) holds with prices $p_{h}^{c_{i}}=p_{h}^{w}$ being the world prices in a frictionless free-trade equilibrium - that is, each is the price that would prevail in all countries if there were no costs of trade whatsoever, neither natural nor artificial. 
The first of these definitions is by far the simplest, and it has the advantage that, by not requiring prices at all, it does not depend on which prices are used. On the other hand, it completely ignores all information about the technology for using intermediate inputs, as well as their costs, and it therefore seems unlikely to be of much use.

The rest of the definitions all build on the comparisons in equation (3), using the same technological parameters in each case but using different prices. With autarky prices, the definition depends only on primitives of the separate countries, and in fact in the Ricardian model these autarky prices depend only on the production parameters of the country, so this may seem the obvious extension of (1) to the case of intermediate goods.

This definition, Definition 2, also seems the most obvious extension of comparative advantage to intermediate inputs using the standard geometric analysis often used to examine the Ricardian Model. As can be verified, ${ }^{4}$ in the familiar case of two countries and two goods, one or both of which may be used as final goods as well as intermediate inputs into the other, each country has a linear transformation curve in twodimensions the slope of which is exactly the ratio in (3) evaluated at autarky prices, which are in turn just the country's own direct-plus-indirect labor requirements. In this case the pattern of trade is fully determined by these relative autarky prices, exactly as in the Ricardian Model without intermediate inputs.

However, this result depends crucially on there being only two goods. Suppose that direct labor requirements for a sector are relatively low, creating comparative advantage if it were not for intermediate inputs. If that sector uses an input from another sector that is costly, then in general that might undermine that comparative advantage. But with only two goods, the input comes from the only other sector in the economy, and 
a costly input therefore means a costly output in that other sector as well. Thus the cost of the input cannot raise cost in the using industry any more than it raises cost in the other industry to which it is compared, and therefore it cannot reverse the pattern of comparative advantage.

For the geometrically inclined, ${ }^{5}$ Figure 1 shows an example, with three goods and two countries, in which the relative autarky prices of two of the goods fail to predict their trade when all three goods are freely traded. The top panel shows the transformation surface, TTT, of a large country, A. Good X is assumed here to be a final good produced without any intermediate input. Good $\mathrm{Y}$ is also a final good, but its production requires an intermediate input of the third good, Z. Axes represent the net outputs of each good, which is a relevant distinction only for $Z$, where the axis measures the gross output of $Z$ minus the use of $\mathrm{Z}$ as input to $\mathrm{Y}$. Thus the peak of TTT, where all A's labor is used to produce $\mathrm{Y}$, requires a net use of $\mathrm{Z}$, which would have to be imported from abroad. In Autarky, country A will have to consume in the X-Y plane, along $\widetilde{T} T$.

The bottom panel shows the second country, B, which I assume to be much smaller than A and therefore draw as 10 times its actual size for visibility. Its transformation surface, SSS, has the same meaning at A's, but with different technical coefficients its slopes are different. In particular, I assume that while its direct labor requirement for $\mathrm{Y}$ is less than $\mathrm{A}$ 's, its labor requirement for $\mathrm{Z}$ is much larger. ${ }^{6}$ The result is that B's relative autarky cost of $\mathrm{Y}$ is higher than A's, giving it a lower relative autarky

\footnotetext{
${ }_{5}^{4}$ And indeed was done for me by a referee.

${ }^{5}$ Including the referee in the previous footnote.

${ }^{6}$ For the numerically inclined, the following parameters have the same qualitative properties as the graphed example: $a_{L X}^{A}=a_{L X}^{B}=1, a_{L Y}^{A}=2, a_{L Y}^{B}=1, a_{L Z}^{A}=1, a_{L Z}^{B}=4, b_{Z Y}^{A}=b_{Z Y}^{B}=1$.
} 
price of X compared to Y as reflected in its flatter line $\widetilde{S} S$ as compared to $\widetilde{T} T$. Autarky prices would therefore predict that B would export X.

However, when these countries are opened to free and frictionless trade, the small size of B assures that it cannot supply all the world's needs of any good, so world prices become the autarky prices of the large country, A. To see what B will produce, simply move the transformation surface of A, TTT, down to the bottom panel and use it as a price plane for $\mathrm{B}$, as is done with the faintly drawn large triangle in the bottom panel. For the shapes drawn, this price plane touches only the top peak of SSS, implying that with trade country B will produce only good Y, and that it will import both $\mathrm{X}$ and $\mathrm{Z} .^{7}$ Thus, the relative autarky prices (which can be seen in the lower panel by comparing the slopes of $\widetilde{S} S$ to $\widetilde{T} \widetilde{T}$ ) have incorrectly predicted the trade pattern.

Thus the Definition 2 in terms of autarky prices misses what can be a very important way that intermediate inputs and comparative advantage interact: A country may export a good whose autarky cost is relatively high if it can replace a high-cost input with a cheaper one imported from abroad. As McKenzie (1954, p. 179) observed, "A moment's consideration will convince one that Lancashire would be unlikely to produce cotton cloth if the cotton had to be grown in England." It is this possibility that suggests that some of the other definitions listed above may be useful. I will explore this possibility further later on.

As will become apparent later, definitions based on (3), even though they may seem like obvious extensions of (1), do not turn out to be as useful as one might have

\footnotetext{
${ }^{7}$ Using the numbers from the previous footnote and an autarky wage of 1 in both countries, autarky prices turn out to be: $p_{X}^{A}=p_{X}^{B}=1, p_{Y}^{A}=3, p_{Y}^{B}=5, p_{Z}^{A}=1, p_{Z}^{B}=4$. With a labor endowment of 10 in $\mathrm{B}$, its value of net output at A's prices is then 10 if it produces only $\mathrm{X}$ or Z, but 20 if it produces only $\mathrm{Y}$.
} 
hoped. The ratios in (3) compare the labor costs per unit of producing goods. An alternative approach that turns out to work better compares the labor required for activities, and focuses on the value added in those activities rather than on units of goods.

That is, consider the activity in a country of producing any good, intermediate or final, using whatever intermediate inputs are required for its production in that country. As before, the labor required for that activity is $a_{g}^{c}$ per unit of the good. But the value of that activity, and thus the labor required per unit of value added, depends also on the price of the good, the prices of all required intermediate inputs, and the quantities of those inputs that are needed. That is, the value added per unit of the good produced is ${ }^{8}$

$$
v_{g}^{c}=p_{g}^{c}-\sum_{h} p_{h}^{c} b_{h g}^{c}
$$

The labor required per dollar of value added in the activity of producing good $g$ from intermediate inputs is then

$$
\alpha_{g}^{c}=\frac{a_{g}^{c}}{v_{g}^{c}}
$$

If we now express comparative advantage in terms of activities and their values added, we would say that country $c_{1}$ has a comparative advantage in (the last stage of production of) good $g_{1}$, relative to good $g_{2}$ and compared to country $c_{2}$, if

$$
\frac{\alpha_{g_{1}}^{c_{1}}}{\alpha_{g_{2}}^{c_{1}}}=\frac{a_{g_{1}}^{c_{1}} / \nu_{g_{1}}^{c_{1}}}{a_{g_{2}}^{c_{1}} / v_{g_{2}}^{c_{c_{2}}}}<\frac{a_{g_{1}}^{c_{2}} / \nu_{g_{1}}^{c_{2}}}{a_{g_{2}}^{c_{2}} / v_{g_{2}}^{c_{2}}}=\frac{\alpha_{g_{1}}^{c_{2}}}{\alpha_{g_{2}}^{c_{2}}}
$$

or, expressing value added in terms of prices and labor requirements, if

\footnotetext{
${ }^{8}$ Attention to value added, and this definition in particular, puts one in mind of the large literature on effective protection initiated by Corden (1966). He defined the effective rate of protection as the effect of a tariff structure on this measure of value added. As far as I can see, although useful under certain assumptions for predicting the effects of tariffs on production, this literature has little bearing on the definition of comparative advantage.
} 


$$
\frac{a_{g_{1}}^{c_{1}} /\left(p_{g_{1}}^{c_{1}}-\sum_{h} p_{h}^{c_{1}} b_{h g_{1}}^{c_{1}}\right)}{a_{g_{2}}^{c_{1}} /\left(p_{g_{2}}^{c_{1}}-\sum_{h} p_{h}^{c_{1}} b_{h g_{2}}^{c_{1}}\right)}<\frac{a_{g_{1}}^{c_{2}} /\left(p_{g_{1}}^{c_{2}}-\sum_{h} p_{h}^{c_{2}} b_{h g_{1}}^{c_{2}}\right)}{a_{g_{2}}^{c_{2}} /\left(p_{g_{2}}^{c_{2}}-\sum_{h} p_{h}^{c_{2}} b_{h g_{2}}^{c_{2}}\right)}
$$

As a definition of comparative advantage, when spelled out fully in (7), this looks daunting, but the comparison that it makes - of labor required per unit of value added - is really quite straightforward. It is true that the expression for value added is cumbersome, but not much more so than the calculation of total costs of goods in (3). And like (3), it acknowledges that comparative advantage depends not only on direct labor cost, but also on the costs and quantities of required inputs. The difference is that the role of the latter is now viewed not as a component of cost, but rather as a deduction from the benefit, or value created by an activity. Again, however, whether this is a more useful formulation of comparative advantage than (3) will depend on what implications may be derived from it. That will be the subject of the rest of the paper.

Also like (3), the definition of comparative advantage in (6) requires not just technological parameters but also prices, and these prices can be selected in various ways. Analogous to Definitions 2-5, these prices can come from autarky, from free and frictionless trade, or from somewhere in between. I therefore name the following definitions, the details of which can be filled in by analogy to Definitions 2-5, but using relationship (6):

Comparative Advantage Definition 2v (Total costs per value added at autarky prices)

\section{Comparative Advantage Definition 3v (Total costs per value added at actual} prices)

\section{Comparative Advantage Definition 4v (Total costs per value added at} undistorted - i.e., free-trade - prices) 


\section{Comparative Advantage Definition 5v (Total costs per value added at frictionless free trade prices)}

\section{The Basic Implication of Comparative Advantage}

Consider now a world with any numbers of countries, $c=1 \ldots C$, and of goods, $g=1 \ldots G$. All are produced with labor and, possibly, intermediate inputs of any or all goods. Some of these goods may only be final goods, others may only be intermediate, and some may be both. Production of one unit of good $g$ in country $c$ requires direct input of $a_{g}^{c}$ units of labor and intermediate inputs of $b_{h g}^{c}$ units of good $h=1 \ldots G$, many or all of which may of course be zero. The actual price of each good $g$ prevailing in country $c$ is $p_{g}^{c}$, and at those prices, the value added per unit of good $g$ is as given in (4). The wage in any activity divides this value added across the labor required. Thus, with perfect competition, the wage in country $c$ is

$$
w^{c}=\max _{g}\left(v_{g}^{c} / a_{g}^{c}\right)
$$

Therefore, if country $c$ produces good $g_{1}$ and not $g_{2}$, then it must be true that ${ }^{9}$

$$
\frac{v_{g_{1}}^{c}}{a_{g_{1}}^{c}}=w^{c} \geq \frac{v_{g_{2}}^{c}}{a_{g_{2}}^{c}}
$$

If country c's producers would actually make a loss producing $g_{2}$, then I will say that country $c$ strictly does not produce $g_{2}$, and the inequality in (9) becomes strict. Therefore, in that case,

\footnotetext{
${ }^{9}$ Note that this comparison and those that follow from it below do not require that trade be balanced.
} 


$$
\frac{a_{g_{1}}^{c}}{a_{g_{2}}^{c}}<\frac{v_{g_{1}}^{c}}{v_{g_{2}}^{c}}=\frac{p_{g_{1}}^{c}-\sum_{h} p_{h}^{c} b_{h g_{1}}^{c}}{p_{g_{2}}^{c}-\sum_{h} p_{h}^{c} b_{h g_{2}}^{c}}
$$

Alternatively, one can rearrange this to say that, if $c$ produces $g_{1}$ and strictly not $g_{2}$, then

$$
\frac{\alpha_{g_{1}}^{c}}{\alpha_{g_{2}}^{c}}=\frac{a_{g_{1}}^{c} / v_{g_{1}}^{c}}{a_{g_{2}}^{c} / v_{g_{2}}^{c}}<1
$$

If we now compare two countries, one of which produces $g_{1}$ and the other $g_{2}$, we have the following proposition, which holds regardless of whether the countries are trading freely or not:

Proposition 1: If country $c_{1}$ produces $g_{1}$ and strictly not $g_{2}$, and if another country $c_{2}$ produces $g_{2}$, then

$$
\frac{a_{g_{1}}^{c_{1}} / v_{g_{1}}^{c_{1}}}{a_{g_{2}}^{c_{1}} / v_{g_{2}}^{c_{1}}}<\frac{a_{g_{1}}^{c_{2}} / v_{g_{1}}^{c_{2}}}{a_{g_{2}}^{c_{2}} / v_{g_{2}}^{c_{2}}}
$$

or equivalently

$$
\frac{a_{g_{1}}^{c_{1}} / v_{g_{1}}^{c_{1}}}{a_{g_{1}}^{c_{2}} / v_{g_{1}}^{c_{2}}}<\frac{a_{g_{2}}^{c_{1}} / v_{g_{2}}^{c_{1}}}{a_{g_{2}}^{c_{2}} / v_{g_{2}}^{c_{2}}}
$$

What this says is that what a country produces - and thus its trade - depends as always on its direct unit labor requirements in production of goods, $a$, compared to those of other countries. But now it also depends on the quantities of intermediate goods that the countries require in production, as these are embodied in the value-added terms, $v$. The $v$ 's depend negatively on these intermediate input requirements, so the ability to produce with a small quantity of an intermediate input will contribute to a large $v$, a low $a / v$, and hence the ability to produce the final good cheaply. However, as is clear in the definition of value added (4), the importance of a particular intermediate input 
requirement $b_{h g}$ also depends on the price of the input $h$. A small intermediate input requirement does not contribute much to lowering comparative cost if the price of that input (in all countries) is also small.

Proposition 1 says that, of the various definitions of comparative advantage put forth earlier in the paper, the one that accurately conforms with the pattern of trade is Definition 3v. That is, we need to compare costs per dollar of value added, not costs per unit, in order to infer the pattern of trade, and furthermore this value added needs to be calculated at the actual prices that prevail in the trading equilibrium. As will be discussed later, this is not ideal, for a theory that is supposed to predict the pattern of trade.

\section{Chains of Comparative Advantage}

As in the case without intermediate inputs, Proposition $1 \mathrm{can}$, in the following special cases, be used to identify patterns of specialization on the basis of "chains" of comparative advantage. For any two countries, for example, and with many goods, the goods can be ranked in order of the ratios in $\left(12^{\prime}\right)$ to produce such a "goods-chain." That is,

Corollary 1 (Goods Chain of Comparative Advantage): Let there be $G$ goods produced by either or both of two countries, $c_{1}$ and $c_{2} .{ }^{10}$ Suppose that the goods have been numbered in order of country $c_{1}$ 's comparative advantage relative to country $c_{2}$; that is, such that

$$
\frac{a_{1}^{c_{1}} / v_{1}^{c_{1}}}{a_{1}^{c_{2}} / v_{1}^{c_{2}}} \leq \frac{a_{2}^{c_{1}} / v_{2}^{c_{1}}}{a_{2}^{c_{2}} / v_{2}^{c_{2}}} \leq \ldots \leq \frac{a_{G}^{c_{1}} / v_{G}^{c_{1}}}{a_{G}^{c_{2}} / v_{G}^{c_{2}}}
$$

\footnotetext{
${ }^{10}$ If there are only two countries, then this covers all goods since they must be produced somewhere. If there are more than two countries, then this excludes goods that are strictly not produced in either, about which this particular chain says nothing.
} 
Sort the goods into three groups: (I) that are produced strictly only by country 1 , (II) that are, or with zero profit could be, produced in both countries, and (III) that are produced strictly only in country 2 . Then group I must lie to the left of group II in this chain, and group III must lie to the right. If there are any goods in group II, the ratios of (13) are the same for each of them.

Similarly, using (12), we can also produce a "country chain" of comparative advantage for any pair of goods:

Corollary 2 (Country Chain of Comparative Advantage): Let there be $C$ countries, all of which produce either or both of two goods, $g_{1}$ and $g_{2}{ }^{11}$ Suppose that the countries have been numbered in order of their comparative advantage in good $g_{1}$ relative to good $g_{2}$; that is, such that

$$
\frac{a_{g_{1}}^{1} / v_{g_{1}}^{1}}{a_{g_{2}}^{1} / v_{g_{2}}^{1}} \leq \frac{a_{g_{1}}^{2} / v_{g_{1}}^{2}}{a_{g_{2}}^{2} / v_{g_{2}}^{2}} \leq \ldots \leq \frac{a_{g_{1}}^{C} / v_{g_{1}}^{C}}{a_{g_{2}}^{C} / v_{g_{2}}^{C}}
$$

Sort the countries into three groups: (I) that produce good 1 and strictly do not produce good 2, (II) that either do, or with zero profit could, produce both goods, and (III) that produce good 2 and strictly do not produce good 1. Then group I must lie to the left of group II in this chain, and group III must lie to the right. If there are any countries within group II, the ratios of (14) are the same for each of them.

To the extent that the ratios in (13) and (14) can be taken as given, these two corollaries go about as far as one could hope toward predicting patterns of specialization and trade. Only the dividing lines between groups within these chains, between goods exported and imported by country $c_{1}$ (in (13)), or between countries exporting and importing good $g_{1}$ (in (14)), remain to be determined by relative sizes of countries and

\footnotetext{
${ }^{11}$ Analogous to footnote 5 , if there are only two goods, then every country must produce at least one of them, and this covers all countries. But if there are more than two goods, then this excludes countries that produce neither of these and, again, this chain tells us nothing about them.
} 
demands for goods. Likewise, whether goods are traded at all or not - the latter implying that the countries produce goods in common - depends on trade barriers.

But the chain results are less useful than they may appear, because of the presence of actual prices in the definition of value added, $v$, and thus in the ratios that are compared in (12), (13), and (14). Even if these prices are common across countries, as they will be in the special case of free and frictionless trade in all goods, they are still endogenous to a trading equilibrium and are therefore not primitives of the model, from which one would like to be able to predict patterns of trade. They can only be known from within the trading equilibrium, and once that equilibrium is observed, prediction of trade patterns is no longer necessary. Furthermore, in most cases of interest (e.g., reality), trade is not free and frictionless. Therefore these prices differ across countries for a whole variety of reasons, including policies that may be intended to influence the pattern of trade. This makes predictions on the basis of these ratios even more problematic.

Nonetheless, there are several special cases that are of interest, in some of which the role of these prices is neutralized, and these cases may be useful if only as benchmarks. I turn next to these special cases.

\section{Special Cases}

Final Goods, Free Trade: First, suppose that there are no intermediate inputs at all, or that none are needed to produce a particular pair of goods. Then $v_{g}^{c}=p_{g}^{c}$. If in addition there is free and frictionless trade, so that $p_{g}^{c_{1}}=p_{g}^{c_{2}}$, then (12) reduces to (1) 
above, the standard expression for Ricardian comparative advantage. ${ }^{12}$ Thus, for example, the presence of intermediate inputs in the larger economy does not undermine the strong implications of Ricardian comparative advantage for pairs of industries that do not use them.

Identical Intermediate Input Requirements, Free Trade: Second, suppose there do exist intermediate inputs, but that two countries share the same intermediate input requirements for the two goods being compared. Then if all ${ }^{13}$ prices in the two countries are the same due to free and frictionless trade between them (including trade in the intermediate inputs), it follows that the $v$ 's are the same in the two countries and they cancel out in (12). Thus once again, comparative advantage depends only on the direct labor requirements, as in (1).

Identical Intermediate Input Requirements, Restricted Trade: On the other hand, even if intermediate input requirements are the same, the presence of trade costs and trade barriers can cause them to matter differently for costs and thus to alter comparative advantage as reflected in these ratios. For example, a country with a relatively low direct labor requirement for producing a good may fail to have a comparative advantage in that good if trade barriers cause the cost of an intermediate input to be high. I will illustrate this possibility with an example later in the paper.

Non-Identical Intermediate Input Requirements, Free Trade: Finally, in what may seem the most natural extension of Ricardian comparative advantage to the presence

\footnotetext{
${ }^{12}$ In fact, as is well known, if there are no intermediate inputs, then (9) holds even in the presence of nonnegative trade barriers, so long as $c_{1}$ exports $g_{1}$ to $c_{2}, c_{2}$ exports $g_{2}$ to $c_{1}$, and one of the countries strictly does not produce the other's export. For together these conditions imply $w^{c_{1}} a_{g_{1}}^{c_{1}} \leq w^{c_{2}} a_{g_{1}}^{c_{2}}$ and $w^{c_{1}} a_{g_{2}}^{c_{1}} \geq w^{c_{2}} a_{g_{2}}^{c_{2}}$, with strict inequality in one of these. Dividing the first by the second yields (1).

${ }^{13}$ Actually, identical prices are needed only for the two goods being compared and their respective inputs.
} 
of intermediate inputs, we can assume free and frictionless trade together with international differences in intermediate input requirements. That is, just as countries differ in the productivity with which they convert labor into goods, they may also differ in their productivity of converting intermediate inputs into outputs. Then comparative advantage can derive just as well from a country having low intermediate input requirements for a particular good as from requiring a relatively small amount of labor.

Suppose, for example, that a country is unusually adept at avoiding waste of the raw material from which a product is made. It could then have a comparative advantage in that product as a result, even if it requires a somewhat larger relative direct input of labor. The same could be true for a country that needs smaller inputs of, say, energy, due perhaps to a favorable climate.

\section{Input Requirements versus Labor Requirements}

There is one difference, however, between the role of intermediate inputs and the role of labor in determining comparative advantage. With labor, the absolute requirement is immaterial for the viability of a sector, since a large absolute requirement can be offset by a low wage. That, in fact, is why trade depends on comparative advantage rather than absolute advantage. ${ }^{14}$ But to the extent that the inputs themselves are tradable, no such offsetting domestic price adjustment may be possible for a country in a sector that is, say, wasteful in its application of intermediate inputs. Such waste could put it at a disadvantage in all sectors, even if direct labor requirements are low. This would also require a fall in its labor's wage in order to compensate and create comparative advantage 
in some sectors. And if sufficiently extreme, high input requirements may cause the value added in one or more sectors to be negative at world prices, so that no reduction in the wage will be enough to create comparative advantage in those particular sectors.

It may seem (as it seemed to me, briefly) that this could happen in all sectors, making it impossible for a country to compete in any of them. If so, that would be an important difference from the Ricardian model without intermediate inputs, where a country must always have a comparative advantage in at least one good, which it can exploit if its wage is low enough. That is, looking at the definition of $v_{g}^{c}$ in (4), what if a country's input requirements $b_{h g}^{c}$ are so large, and/or the output prices $p_{g}^{c}$ are so small, perhaps due to free trade with lower-cost countries, that $v_{g}^{c}<0$ for all $g$ ? That would seem to mean that the entire economy would fail to be viable at all at those prices, and perhaps that cutting itself off from free trade would be the only way to survive.

In fact, this cannot happen in equilibrium if the input-output technology permits production at all, even in a closed economy. According to Gale (1960), a "productive" economy must have the matrix $(I-B)^{-1}$ be non-negative in order for it to be possible to use up smaller amounts of goods as inputs than are produced as output, where $B$ is the matrix of the economy's input-output coefficients $b_{h g}^{c}$ as defined in (4) above. ${ }^{1516}$ Thus, letting $v$ and $p$ be (row) vectors of country $c$ 's value added and prices, (4) becomes

\footnotetext{
${ }^{14}$ Unless labor is mobile so as to prevent a wage differential between the countries, in which case absolute advantage matters after all.

${ }^{15}$ The matrix $B$ has dimension equal to the number of all goods, both final, intermediate, and both. If a good uses no produced inputs to its production, then $b_{h g}^{c}=0$ for all $h$, and the $h^{\prime}$ th row of $B$ is all zeros. This does not interfere with $I-B$ having an inverse.

${ }^{16}$ See Gale (1960, p. 297). To see this, let $X$ and $Y$ be row vectors of gross and net outputs, respectively. Then $Y=X-X B^{\prime}$, and thus $Y\left(I-B^{\prime}\right)^{-1}=X$. That is, the rows of $\left(I-B^{\prime}\right)^{-1}-$ and thus the
} 


$$
v=p(I-B)
$$

and thus

$$
v(I-B)^{-1}=p
$$

For a productive economy in the sense of Gale, then, $v<0$ requires $p<0$ as well. Thus, as long as prices are non-negative, value added per unit cannot be negative for all goods. Instead, there must be at least one good for which production is viable in a productive economy that faces any given nonnegative prices $p$.

\section{Gains from Trade}

Indeed, this same condition - that the economy be "productive" or $(I-B)^{-1}$ be nonnegative - also assures that there are gains from trade, which in the Ricardian Model simply means that the real wage rises with trade. Let $\widetilde{w}$ be the (scalar) wage in autarky and $\widetilde{p}$ the vector of autarky prices, with corresponding $\widetilde{v}=\widetilde{p}(I-B)$. Since all goods are produced in autarky, we must have $\widetilde{w}=\widetilde{v}_{g} / a_{g} \forall g$, while (8) implies that $w \geq v_{g} / a_{g} \forall g$ in any trading equilibrium. Together these imply $\widetilde{v}_{g} / \widetilde{w} \geq / v_{g} / w$, which can be arranged, using (4), as//

$$
\left(\frac{\widetilde{p}_{g}}{\widetilde{w}}-\frac{p_{g}}{w}\right)-\sum_{h}\left(\frac{\widetilde{p}_{h}}{\widetilde{w}}-\frac{p_{h}}{w}\right) b_{h g} \geq 0
$$

Expressed in terms of the vectors of prices, $\widetilde{p}$ and $p$ (since $\widetilde{w}$ and $w$ are scalars), this is

$$
\left(\frac{\widetilde{p}}{\widetilde{w}}-\frac{p}{w}\right)(I-B) \geq 0
$$

If $(I-B)^{-1} \geq 0$, then post-multiplying by it preserves the inequality, and thus

columns of $(I-B)^{-1}$ - are the gross outputs needed to produce a net output of one unit of each individual good. These must be nonnegative for viability as a closed economy. 


$$
\left(\frac{\widetilde{p}}{\widetilde{w}}-\frac{p}{w}\right) \geq 0
$$

That is, $w / p_{g} \geq \widetilde{w} / \widetilde{p}_{g} \forall g$, meaning that the real wage is at least as high with trade as

without, in terms of every good. In addition, these inequalities are strict for every good that is strictly not produced in the trading equilibrium, and they may in fact be strict for goods that are produced as well, if cheap imported intermediate inputs lower their prices compared to autarky.

Proposition 2 (Gains from Trade): In the Ricardian Model, the wage of labor is at least as high in terms of every good with trade as it is in autarky. It is also strictly higher for goods that are themselves strictly not produced in the trading equilibrium, and also for goods that use positive amounts, directly or indirectly, of inputs that are themselves strictly not produced. That is,

$$
\frac{w}{p_{g}} \geq \frac{\widetilde{w}}{\widetilde{p}_{g}} \quad g=1, \ldots, G
$$

and also

$$
\begin{aligned}
& \frac{w}{p_{g}}>\frac{\widetilde{w}}{\widetilde{p}_{g}} \\
& \quad \text { if } a_{g}>\frac{v_{g}}{w} \\
& \quad \text { or if } b_{h g}>0 \text { for some } h \text { such that } \frac{w}{p_{h}}>\frac{\widetilde{w}}{\tilde{p}_{h}}
\end{aligned}
$$

Proof: (21) follows from (20). For (22), first note that

$$
\begin{gathered}
\widetilde{p}_{g}=\widetilde{w} a_{g}+\sum_{h} \widetilde{p}_{h} b_{h g} \\
p_{g} \leq w a_{g}+\sum_{h} p_{h} b_{h g}
\end{gathered}
$$

Then for (22a), 


$$
\begin{aligned}
a_{g}>\frac{v_{g}}{w} & \Rightarrow w a_{g}>p_{g}-\sum_{h} p_{h} b_{h g} \\
& \Rightarrow \frac{p_{g}}{w}<a_{g}+\sum_{h} \frac{p_{h}}{w} b_{h g} \leq a_{g}+\sum_{h} \frac{\widetilde{p}_{h}}{\widetilde{w}} b_{h g}=\frac{\widetilde{p}_{g}}{\widetilde{w}}
\end{aligned}
$$

where the last inequality uses (21) and the last equality uses (23).

Similarly for (22b), suppose that for some $h_{1}, b_{h_{1} g}>0$ and $w / p_{h_{1}}>\widetilde{w} / \widetilde{p}_{h_{1}}$, perhaps due to (22a). Then from (24)

$$
\begin{aligned}
\frac{p_{g}}{w} & \leq a_{g}+\sum_{h \neq h_{1}} \frac{p_{h}}{w} b_{h g}+\frac{p_{h_{1}}}{w} b_{h_{1} g} \\
& <a_{g}+\sum_{h \neq h_{1}} \frac{p_{h}}{w} b_{h g}+\frac{\widetilde{p}_{h_{1}}}{\widetilde{w}} b_{h_{1} g} \\
& \leq a_{g}+\sum_{h \neq h_{1}} \frac{\widetilde{p}_{h}}{\widetilde{w}} b_{h g}+\frac{\widetilde{p}_{h_{1}}}{\widetilde{w}} b_{h_{1} g}=\frac{\widetilde{p}_{g}}{\widetilde{w}}
\end{aligned}
$$

where again the last inequality uses (21) and the last equality uses (23).

This is a stronger result than we find in the textbook, 2-good, Ricardian Model without intermediate inputs. There, with specialization, the real wage rises in terms of one good - the one that is not produced - but not in terms of the other. The result here is stronger: the real wage rises in terms of goods that continue to be produced, and perhaps in terms of all goods if the use of intermediate inputs is sufficiently ubiquitous. The reason is illustrated in two cases shown in the two panels of Figure 2.

In both panels, the axes measure net output of goods - two of them in panel A and three in panel B. In both, the points labeled $T$ and the solid lines connecting them mark the extremes of the (linear) transformation curve or surface. In panel A, each of the two goods is assumed to be required as an input to the other, so that the maximum net output of either (achieved by devoting all labor to its production) requires a negative net output 
of the other. In panel B, goods 1 and 2 are only final goods, while good 3 is a required intermediate input to production of both of them.

Autarky requires production of all goods and thus operation on the interior of the transformation curve or surface, $T$, within the positive orthant. Defining one unit of labor as the labor endowment, the intercepts of $T$ measure the autarky wage in units of each good, $\widetilde{w} / \widetilde{p}_{g}$, as shown.

With trade, producers respond to prices that are different from autarky, maximizing the nominal wage at one of the extremes of $T, Q$ (or perhaps, in panel B, along one of its edges). Consumption takes place within the positive orthant on the new price line or plane, $P$, passing through the production point $Q$. In both cases, this permits an increase in consumption of both goods 1 and 2, and in panel B of good 3 as well. The real wages with trade are identified as the intercepts of the price line or plane, $P$, with the axes, $w / p_{g}$.

In the example of panel $\mathrm{A}, w / p_{1}$ rises with trade because good 1 is strictly not produced. At the same time, $w / p_{2}$ also rises, even though good 2 is produced, because it is produced with the now cheaper input of good 1. The same is true in panel B, except that now it is a third good, 3 , that serves as the cheaper input for both final goods.

I have discussed the model as though intermediate inputs are traded. However, Propositions 1 and 2 hold just as well with nontraded inputs as with traded ones. The difference is that now a country's price of an input is likely to become an important determinant of comparative advantage. If a nontraded input is not produced but merely available as an endowment, then abundance will cause it to be cheap and the value added 
in industries that use it will be relatively high, thus contributing to comparative advantage. On the other hand, if nontraded inputs are produced from labor like any other good, then comparative advantage in sectors that use them will come to depend in part on the country's labor requirements for producing such inputs. ${ }^{17}$ It is this fact, together with the fact that the tradability of most inputs is to some extent a policy choice, that prevents us from going much further in formulating comparative-advantage-based predictions of trade patterns that are both robust and precise, even in the Ricardian Model, as I now show.

\section{Impossibility of a Fixed Chain of Ricardian Comparative Advantage}

Corollary 1 seems to say that, if there are only two countries in a Ricardian world, then we should be able to rank goods by comparative advantage and predict patterns of trade and specialization with some confidence. In fact, we cannot, if we want the same chain to predict trade patterns independently of whatever barriers to trade may happen to exist. That is, just as is known to be true in the Heckscher-Ohlin Model, ${ }^{18}$ the combination of intermediate inputs and trade barriers renders any fixed chain of comparative advantage not generally valid as a predictor of trade.

To see this in the Ricardian Model, consider a relatively simple case in which two countries produce and trade four goods, of which two are final goods and two serve only

\footnotetext{
${ }^{17}$ In the latter case, there is little purpose served by continuing to interpret an input as a separate good. Its production might as well have been subsumed within the technologies of final goods. Or at least, that is the case if the input is nontradable, as well as nontraded. For other inputs, whether they are traded or not may depend on market conditions, in which case maintaining their separate identity is critical.

${ }^{18}$ See Deardorff (1979).
} 
as inputs to the respective final goods. ${ }^{19}$ To fix ideas, we may call the final goods cloth (C) and autos (A), and the inputs to them respectively wool (W) and steel (S). Suppose that production of one unit of cloth uses one unit of wool and production of an auto uses one unit of steel, with no other intermediate inputs required for any of the goods. Then let the direct unit labor requirements for producing these four goods in two countries, 1 and 2, be as follows:

\begin{tabular}{|r|c|c|c|c|}
\hline \multirow{2}{*}{$\begin{array}{l}\text { Direct unit } \\
\text { labor } \\
\text { requirements }\end{array}$} & \multicolumn{4}{|c|}{ Goods } \\
\cline { 2 - 5 } & $\begin{array}{c}\mathrm{W} \\
\text { Wool }\end{array}$ & $\begin{array}{c}\mathrm{A} \\
\text { Autos }\end{array}$ & $\begin{array}{c}\mathrm{C} \\
\text { Cloth }\end{array}$ & $\begin{array}{c}\text { S } \\
\text { Steel }\end{array}$ \\
\hline Country 1 & 1 & 2 & 3 & 4 \\
\hline Country 2 & 4 & 3 & 2 & 1 \\
\hline
\end{tabular}

If trade is free and frictionless in all four goods, then since intermediate input requirements and prices are the same in both countries, the $v$ 's cancel out of (13) above and we can apply the goods-chain proposition using the ratios of only the direct unit labor requirements in the table. Clearly, country 1's greatest comparative advantage is in wool, second in autos, third in cloth, and last in steel. It will therefore surely produce and export wool, and it will import steel, with the trade in autos and cloth depending on country size. If neither country is too large relative to the other, then country 1 will export autos as well as wool, and import cloth as well as steel. The chain of comparative advantage seems to be working just fine, using the ratios from the table: $1 / 4,2 / 3,3 / 2$, and $4 / 1$.

But now suppose that prohibitively large trade barriers exist for both intermediate inputs, wool and steel, so that they become nontraded. A country that produces autos

\footnotetext{
${ }^{19}$ Figure 1 already provides such an example, though perhaps without the clarity of the example here. In Figure 1, Country B exports $\mathrm{Y}$ and imports $\mathrm{X}$ with free trade in all three goods. If the intermediate goods $\mathrm{Z}$ were subject to prohibitive tariffs, however, B would export $\mathrm{X}$ and import $\mathrm{Y}$.
} 
must then produce its own steel, and a country that produces cloth must produce its own wool. Production of the required input can then be thought of as integrated with that of the final good, and the four-good model reduces to a familiar two-good Ricardian case with the following direct-plus-indirect unit labor requirements:

\begin{tabular}{|r|c|c|}
\hline \multirow{2}{*}{$\begin{array}{l}\text { Direct-plus- } \\
\text { indirect unit labor } \\
\text { requirements }\end{array}$} & \multicolumn{2}{|c|}{ Final Goods } \\
\cline { 2 - 3 } & $\begin{array}{c}\mathrm{A} \\
\text { Autos }\end{array}$ & $\begin{array}{c}\text { C } \\
\text { Cloth }\end{array}$ \\
\hline Country 1 & $2+4=6$ & $3+1=4$ \\
\hline Country 2 & $3+1=4$ & $2+4=6$ \\
\hline
\end{tabular}

Evidently, country 1 now has its comparative advantage in cloth, not autos, and the trade in autos and cloth is the reverse of that above.

The point of this is not just that trade barriers matter for the pattern of trade, which of course they do, here in a rather extreme way. The point is further that there cannot exist a single ranking of the goods in terms of any notion of comparative advantage that will predict their trade in the same sense as the Corollaries above. For any ranking that puts cars to the left of tables - and would therefore be consistent with the pattern of trade in these two goods when all goods are traded freely - would rank them incorrectly for the trade pattern that arises when the intermediate inputs are not traded.

Of course, if we always knew which goods used tradable inputs and which did not, then we could always use direct-plus-indirect unit labor requirements for the latter in defining comparative advantage and then ranking the goods. But the tradability of goods depends on the sizes of trade barriers, and implicit in the above example is the fact that trade patterns can depend so critically on the sizes of these barriers that no ranking of comparative advantage can predict trade independently of those barriers. 


\section{What Can Be Said?}

This is a familiar problem, for it arose in the Heckscher-Ohlin Model in Deardorff (1979). Because of it, I opted in Deardorff (1980) for expressing the role of comparative advantage by means of a correlation between autarky prices and trade flows. ${ }^{20}$ Such a result can be established here:

Proposition 3: Consider a Ricardian economy that trades at prices $p$, with vectors of goods in (gross) production $X$, inputs $N$, and final consumption $C$, so that net output is $X-N$ and net exports are $T=X-N-C$. Then the value at autarky prices $\tilde{p}$ of the country's trade, if $p \neq \widetilde{p}$, must be negative:

$$
\widetilde{p} T^{\prime}=\sum_{g} \widetilde{p}_{g} T_{g}<0
$$

Proof: Consider first the value of net output. It is shown in Appendix B that

$$
\widetilde{p}\left(X^{\prime}-N^{\prime}\right)=\sum_{g} \frac{\widetilde{w}}{w} p_{g}\left(X_{g}-N_{g}\right)
$$

Now use (22) to interpret the value of consumption:

$$
\widetilde{p} C^{\prime}=\sum_{g} \widetilde{p}_{g} C_{g}>\sum_{g} \frac{\widetilde{w}}{w} p_{g} C_{g}
$$

with the strict inequality since $p \neq \hat{p}$ implies that at least one final good or input is strictly not produced. Thus

$$
\begin{aligned}
\widetilde{p} T^{\prime} & =\widetilde{p}\left(X^{\prime}-N^{\prime}\right)-\widetilde{p} C^{\prime} \\
& <\sum_{g} \frac{\widetilde{w}}{w} p_{g}\left(X_{g}-N_{g}\right)-\sum_{g} \frac{\widetilde{w}}{w} p_{g} C_{g} \\
& =\sum_{g} \frac{\widetilde{w}}{w} p_{g}\left(X_{g}-N_{g}-C_{g}\right)=\frac{\widetilde{w}}{w} p T^{\prime}=0
\end{aligned}
$$

by balanced trade. ${ }^{21}$

\footnotetext{
${ }^{20}$ The same correlation result was shown by Dixit and Norman (1980, p. 94).

${ }^{21}$ This actually assumes free trade, as well, since $p$ is serving as both domestic and world prices in the trading equilibrium. As in Deardorff (1980), nonnegative trade barriers can easily be incorporated.
} 
This result is the same as that in Deardorff (1980), but it requires fewer assumptions here than it did there. In a more general model with variable costs, such a correlation result depends not only on producers maximizing the value of the country's output, as they do here implicitly in (8), but also on demand not changing between autarky and free trade in such a way that demand expands even more than output in expanding sectors. In the Ricardian model, because the economy completely specializes, this is not an issue.

Figure 3 illustrates this, for simple 2-good economies without intermediate inputs. Panel A, on the left, shows autarky and trade equilibria with variable costs, while panel B shows the same for a Ricardian economy. In each, the transformation curve is $T T$, and autarky equilibrium is at the point labeled $\widetilde{X}=\widetilde{C}$, with autarky price line $\widetilde{P}$. With free trade at the price $P$, production moves to point $X$, the economies both increasing their output of good $X_{1}$. In panel $\mathrm{A}$, without any further assumption on demand, consumption could move either to point $C$ or point $C^{\prime}$. At $C^{\prime}$, however, the value of consumption at autarky prices is below the value of production, and indeed the country imports good $X_{1}$ in spite of its comparative advantage. To rule this out in Deardorff (1980) I assumed the Weak Axiom of Revealed Preference applied to consumption of the country as a whole, which in effect forced the country to behave like a single consumer and prevented an outcome like $C^{\prime 22}$ But in the Ricardian case of panel B, this is not necessary, since the linear technology leads the country to the corner solution of producing only $X_{1}$ and

\footnotetext{
${ }^{22}$ Without that, consumption at $C^{\prime}$ may be possible if the move from autarky to trade shifts income toward consumers who have a greater preference for good $X_{1}$. For example, in the Heckscher-Ohlin Model, if owners of the two factors have different preferences, the change in goods prices from autarky to free trade will also change factor prices and redistribute income from one group to the other. If owners of the factor used intensively in producing good $X_{1}$ also have a greater preference for consuming it, then movement of consumption to a point like $C^{\prime}$ can occur.
} 
nothing of $X_{2}$. In that case, consumption with trade (so long as both goods are consumed at all), must be worth more at autarky prices than production, and the country must export $X_{1}$. It turns out, as the proof above demonstrates since it requires no assumption about demand, that this same property holds in a Ricardian model with any number of goods as well as with intermediate inputs.

Does this weakened assumption matter? Perhaps not. The obvious reason for something like the Weak Axiom to be violated by a country's aggregate consumption is for trade to redistribute income among groups with different preferences, or among groups with different incomes if preferences are not homothetic. ${ }^{23}$ Yet in a Ricardian model, income derives only from labor, which is paid the same in every industry. So it is hard to see how such redistribution could occur.

It may also be worth noting the role of gains from trade in generating this result. The proof in Deardorff (1980) proceeded in two steps, the first being to show the gains from trade, and then from that to infer the correlation. In effect the same is true here, since the crucial inequality in (27) stems from the comparison of real wages in (22). Thus, even though we need no assumption about preferences here, the tendency for a country to export goods in which it has a comparative advantage continues to be intimately linked with the gain from doing so.

\section{Conclusion}

This paper has examined the role of comparative advantage in a Ricardian trade model with intermediate inputs. A variety of definitions of comparative advantage

\footnotetext{
${ }^{23}$ See previous footnote.
} 
suggest themselves, most of which require the use of prices to evaluate the roles of intermediate inputs. These prices could in principle be taken from any of several actual or hypothetical equilibria. The definition that provides the strongest predictions of trade, in the form of chains of comparative advantage, compares labor per unit of value added, where value added is based on prices that actually prevail in the trading equilibrium.

Unfortunately, these actual prices depend crucially on prevailing barriers to trade, so much so that, without knowledge of these barriers, comparative advantage cannot necessarily even predict the pattern of trade in a pair of goods between a pair of countries. The best that seems to be possible, even in the simplified world of Ricardian assumptions, is a correlation of trade patterns with autarky prices. Thus only an average relationship between comparative advantage and trade seems to be at all robust.

In spite of this, the gains from trade are unambiguous in these Ricardian models, with imported inputs actually providing an additional source of gain from trade. And the weaker correlation version of the Law of Comparative Advantage turns out to be valid under slightly weaker assumptions than in more general models. 


\section{References}

Amano, Akihiro 1966 "Intermediate Goods and the Theory of Comparative Advantage: A Two-Country, Three-Commodity Case," Weltwirtschaftliches Archiv, pp. 340345.

Corden, W. Max 1966 "The Structure of a Tariff System and the Effective Protective Rate," Journal of Political Economy 74, pp. 221-237.

Deardorff, Alan V. 1979 "Weak Links in the Chain of Comparative Advantage," Journal of International Economics 9, (May), pp. 197-209.

Deardorff, Alan V. 1980 "The General Validity of the Law of Comparative Advantage," Journal of Political Economy 88, (October), pp. 941-957.

Deardorff, Alan V. 2001 "Fragmentation in Simple Trade Models," North American Journal of Economics and Finance 12, (July), pp. 121-137.

Dixit, Avinash K. and Gene M. Grossman 1982 "Trade and Protection with Multistage Production," Review of Economic Studies 59, pp. 583-594.

Dixit, Avinash K. And Victor Norman 1980 Theory of International Trade, London: Cambridge University Press.

Gale, David 1960 The Theory of Linear Economic Models, New York: McGraw Hill.

Graham, Frank D. 1923 "The Theory of International Values Re-Examined," Quarterly Journal of Economics 38, November, pp. 54-86.

Graham, Frank D. 1948 The Theory of International Values, Princeton: Princeton University Press.

Grossman, Gene M. and Elhanan Helpman 2002 "Integration versus Outsourcing in Industry Equilibrium," Quarterly Journal of Economics 117, pp. 85-120.

Feenstra, Robert C. and Gordon H. Hanson 2003 "Global Production Sharing and Rising Inequality: A Survey of Trade and Wages," in Kwan Choi and James Harrigan, eds., Handbook of International Trade, London: Basil Blackwell, forthcoming.

Haberler, Gottfried 1936 Theory of International Trade, translated from the 1933 German edition by Alfred Stonier and Frederic Benham, London: William Hodge \& Co.

Hummels, David, Jun Ishii, and Kei-Mu Yi 2001 "The Nature and Growth of Vertical Specialization in World Trade," Journal of International Economics 54.

Jones, Ronald W. 1961 "Comparative Advantage and the Theory of Tariffs: A MultiCountry, Multi-Commodity Model," Review of Economic Studies 28, (June), pp. 161-175.

Jones, Ronald W. 1980 "Comparative Advantage and Absolute Advantage," Schweizerische Zeitschrift fur Volkswirtschaft und Statistik, pp. 235-259.

Jones, Ronald W. 2000 Globalization and the Theory of Input Trade, Cambridge, MA: MIT Press.

Jones, Ronald W. and J. Peter Neary 1984 "The Positive Theory of International Trade," in R.W. Jones and P.B. Kenen, eds., Handbook of International Economics, Vol. I, New York: North-Holland.

McKenzie, Lionel W. 1954 "Specialisation and Efficiency in World Production," Review of Economic Studies 21, No. 3, pp. 165-180. 
Samuelson, Paul A. 1951 "Abstract of a Theorem Concerning Substitutability in an Open Leontief Model," in Stiglitz, Joseph, ed., Collected Scientific Papers of Paul A. Samuelson, Vol 1, Cambridge, MA: MIT Press, 1966.

Sanyal, Kalyan K. 1983 "Vertical Specialization in a Ricardian Model with a Continuum of Stages of Production," Economica 50, February, 71-78.

Viner, Jacob 1937 Studies in the Theory of International Trade, New York: Harber \& Brothers. 


\section{Appendix A: Previous Literature}

Haberler (1936) devotes a chapter to the Theory of Comparative Costs, most of which is describing what we now call the Ricardian model. However, although he goes well beyond the two-good case to consider multiple goods, transport costs, and variable costs of production, he does not allow for intermediate inputs.

Viner (1937) also devotes his penultimate chapter to Comparative Costs, although he uses the heading Gains from Trade, which may be indicative of what he cares about. He devotes lots of attention to who said what and who made errors - or not - and he extends the theory to multiple countries as well as the extensions mentioned by Haberler. But again, there is no mention of intermediate inputs.

Graham (1948) deals extensively with the Ricardian structure, carefully exploring extensions in all manner of directions, but even his chapter VIII, "Relaxation of Assumptions in the Approach to Reality," fails to mention intermediate inputs.

McKenzie (1954) is mostly about showing that an efficient allocation can be attained with competitive prices. He does this in the model of Graham (1923), which he points out has (and can have, for its purpose) no intermediate inputs. McKenzie does however discuss the importance of intermediate inputs, pointing out that if they are traded they both expand production possibilities and may alter what a country exports. He also points out that the justification for fixed coefficients, which otherwise might be based on Samuelson's (1951) non-substitution result, disappears once intermediate inputs are traded and thus have different prices. Thus, he says, "as soon as trade in intermediate products is allowed, the problem loses its special simplicity, and we may as well allow joint production and many factors in each country.” (p. 179)

Jones (1961) derives a condition for efficient assignment of countries to goods in a many-good, many-country Ricardian model. The condition is to minimize the product of countries' unit labor requirements. He considers the possibility of traded intermediate inputs, and is able to extend this same result in their presence (using direct labor requirements only), but only under the assumption that all countries share the same intermediate input coefficients.

Amano (1966) shows by example why general results are so difficult with intermediate inputs. With two countries and three goods, holding constant the ranking of comparative advantage across the goods, he shows two situations in which the pattern of trade in two of the goods is reversed. Although he does not say so, implicitly the two countries do not share identical intermediate input coefficients.

Jones (1980) makes a point that is made here as well: patterns of comparative advantage depend necessarily on prices. Indeed, in a footnote (p. 240) he describes his earlier frustration in trying to find a criterion for comparative advantage in a Ricardian model with intermediate inputs that would not include prices. Undoubtedly, Amano's counterexample arises because prices matter, and are endogenous.

Jones and Neary (1984) give the central results of Ricardian comparative advantage, but when they get to intermediate inputs, they mostly just stress their importance and refer the reader to McKenzie (1954) without giving anything in the way of results except citing an example from Jones (1980) of how important intermediates can be. 


\section{Appendix B: Derivation of Equation (26)}

Spelling out the vector products as summations and expressing inputs in terms of their input-output coefficients, using a bit of manipulation and the definition (4), the value of net output can be expressed in terms of value added and gross output:

$$
\begin{aligned}
\tilde{p}\left(X^{\prime}-N^{\prime}\right) & =\sum_{g} \tilde{p}_{g}\left(X_{g}-N_{g}\right)=\sum_{g} \tilde{p}_{g} X_{g}-\sum_{g} \widetilde{p}_{g} \sum_{h} b_{g h} X_{h} \\
& =\sum_{g} \widetilde{p}_{g} X_{g}-\sum_{g} \sum_{h} \widetilde{p}_{h} b_{h g} X_{g}=\sum_{g}\left(\widetilde{p}_{g}-\sum_{h} \widetilde{p}_{h} b_{h g}\right) X_{g} \\
& =\sum_{g} \widetilde{v}_{g} X_{g}
\end{aligned}
$$

From (8), $w=v_{g} / a_{g}$ for all $g$ for which $X_{g}>0$, and thus $\widetilde{w}=\widetilde{v}_{g} / a_{g} \forall g$. Thus

$$
\widetilde{v}_{g}=a_{g} \widetilde{w}=v_{g} \widetilde{w} / w \quad \forall g \text { such that } X_{g}>0
$$

Thus, since the final summation in (A1) has nonzero terms only if $X_{g}>0$,

$$
\begin{aligned}
\sum_{g} \widetilde{v}_{g} X_{g} & =\sum_{g} \frac{\widetilde{w}}{w} v_{g} X_{g}=\sum_{g} \frac{\widetilde{w}}{w}\left(p_{g}-\sum_{h} p_{h} b_{h g}\right) X_{g} \\
& =\sum_{g} \frac{\widetilde{w}}{w} p_{g} X_{g}-\sum_{g} \frac{\widetilde{w}}{w} \sum_{h} p_{h} b_{h g} X_{g}=\sum_{g} \frac{\widetilde{w}}{w} p_{g} X_{g}-\sum_{g} \frac{\widetilde{w}}{w} p_{g} \sum_{h} b_{g h} X_{h} \\
& =\sum_{g} \frac{\widetilde{w}}{w} p_{g}\left(X_{g}-N_{g}\right)
\end{aligned}
$$

where again we have mostly manipulated the expressions and reused definitions. Combining (A1) and (A3) yields equation (26) in the text. 

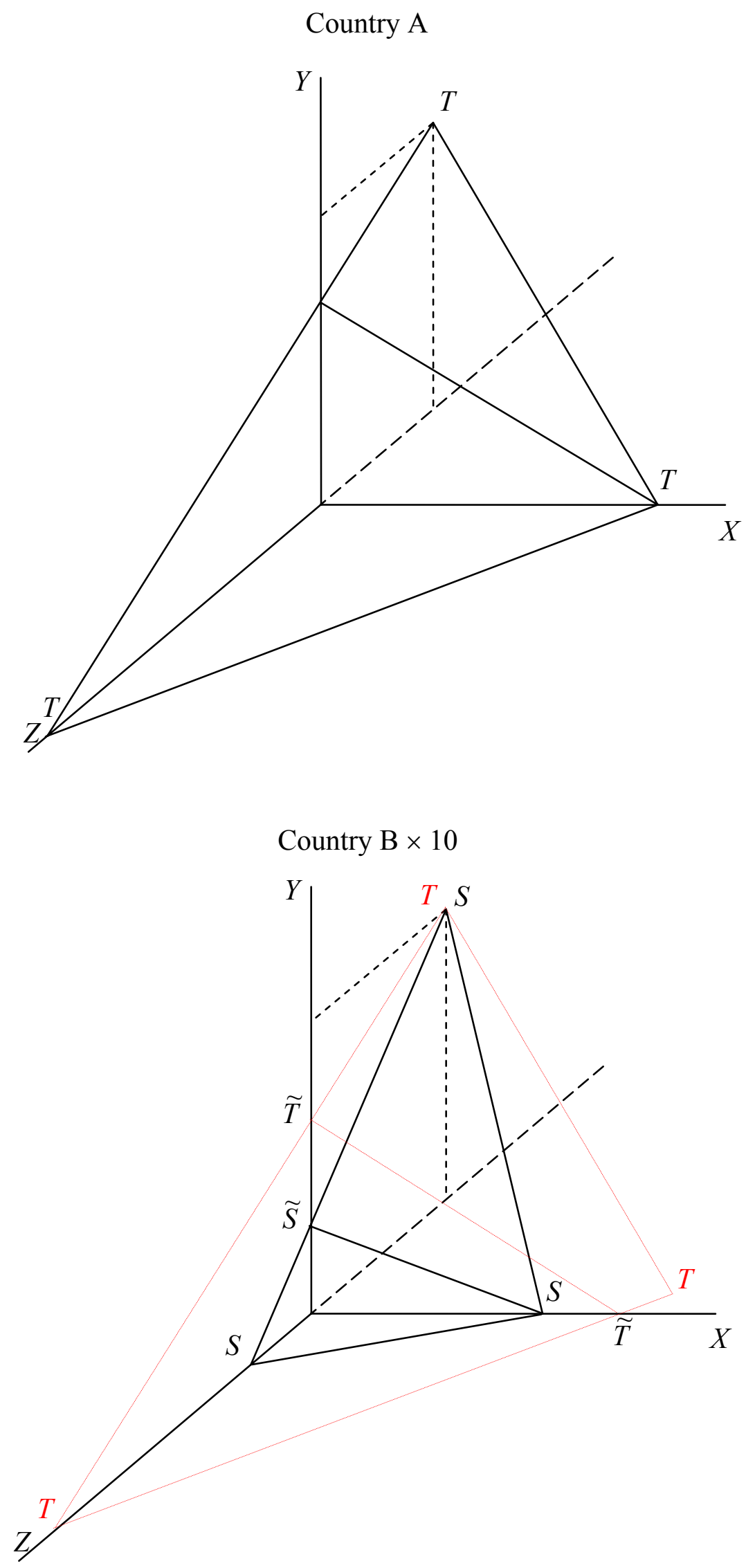

Figure 1 


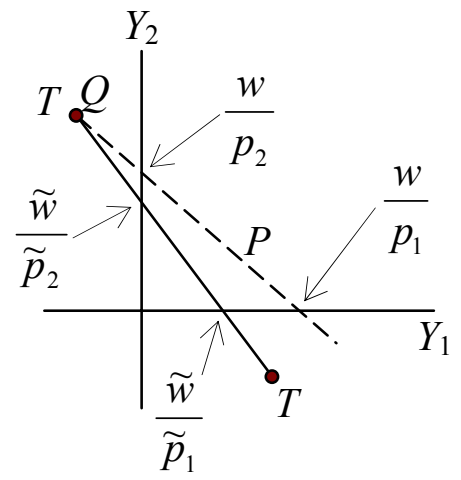

Example A

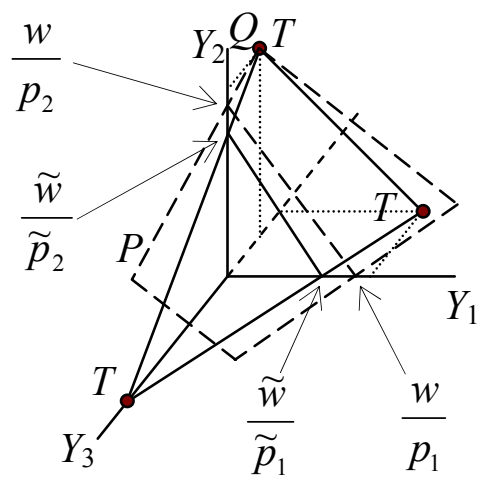

Example B

Figure 2

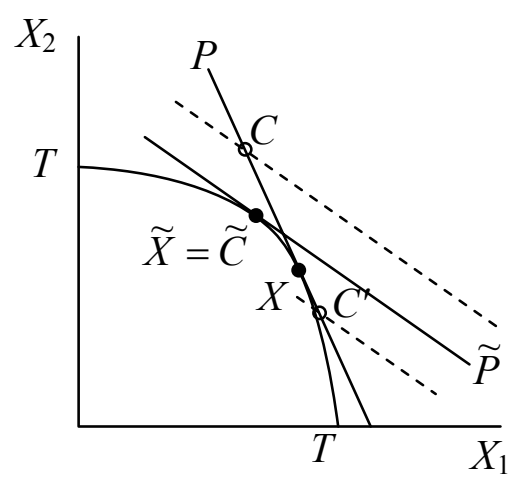

Example A:

Variable costs

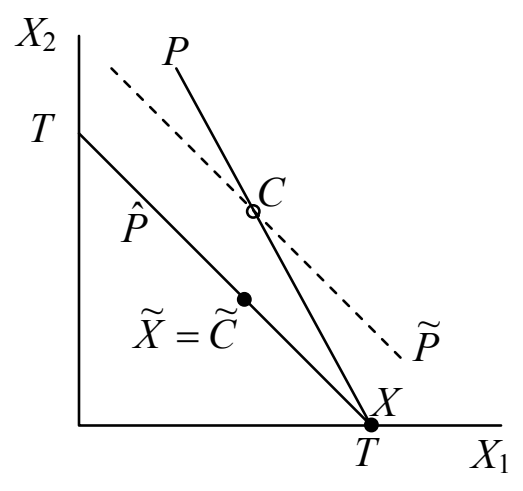

Example B:

Constant costs

Figure 3 